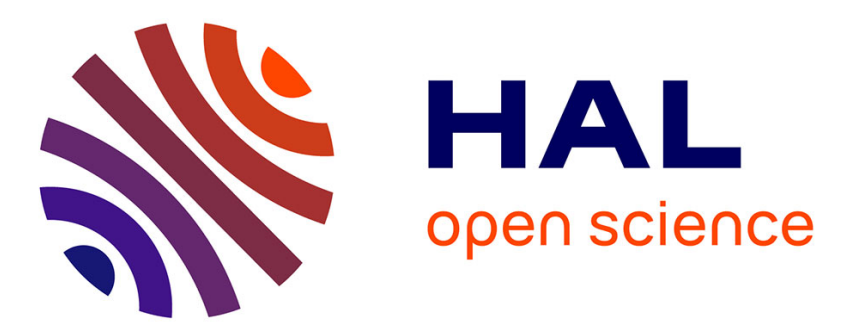

\title{
Population dynamics of the brown alga Himanthalia elongata under harvesting pressure
}

Doriane Stagnol, Renaud Michel, Dominique Davoult

\section{To cite this version:}

Doriane Stagnol, Renaud Michel, Dominique Davoult. Population dynamics of the brown alga Himanthalia elongata under harvesting pressure. Estuarine, Coastal and Shelf Science, 2016, 174, pp.65-70. 10.1016/j.ecss.2016.03.014 . hal-01297341

\section{HAL Id: hal-01297341 https://hal.sorbonne-universite.fr/hal-01297341}

Submitted on 4 Apr 2016

HAL is a multi-disciplinary open access archive for the deposit and dissemination of scientific research documents, whether they are published or not. The documents may come from teaching and research institutions in France or abroad, or from public or private research centers.
L'archive ouverte pluridisciplinaire HAL, est destinée au dépôt et à la diffusion de documents scientifiques de niveau recherche, publiés ou non, émanant des établissements d'enseignement et de recherche français ou étrangers, des laboratoires publics ou privés. 
1 Population dynamics of the brown alga Himanthalia elongata under harvesting pressure.

2 Doriane Stagnol ${ }^{\mathrm{a}, \mathrm{b}^{*}}$, Renaud Michel ${ }^{\mathrm{a}, \mathrm{b}}$, Dominique Davoult ${ }^{\mathrm{a}, \mathrm{b}}$

3 a Sorbonne Universités, UPMC Univ Paris 6, Station Biologique, Place Georges Teissier, F-29682

4 Roscoff, France

$5 \quad{ }^{\mathrm{b}}$ CNRS, UMR 7144 AD2M, Place Georges Teissier, F-29682, Roscoff, France

$6 \quad$ * Corresponding author: Email: doriane.stagnol@gmail.com; Phone: +33 2982923 23; Present address:

7 Station Biologique de Roscoff, Place Georges Teissier, CS 9007429688 Roscoff Cedex, France

8 Abstract

9 Through experimental harvesting, followed by a 12-month monitoring of demographic attributes, we 10 tested the influence of harvesting on the population dynamics of Himanthalia elongata. We further 11 explore the data to test the hypothesis that the canopy would exert a negative effect on the other 12 developmental stages (intraspecific competition) throughout the recovery cycle of the population. This 13 showed that the H. elongata canopy plays a marked seasonal role not by precluding the presence of other 14 developmental stages but by delaying or preventing their growth and development. The removal of the 15 canopy facilitates the transition from one developmental stage to another, eventually permitting a fast 16 recovery of size structure in the population. This study allows us to integrate population dynamics and 17 intraspecific relationships in our understanding of macroalgal recovery patterns.

18 Key-words: intraspecific relationships, intertidal, management, population dynamics, restoration

\section{Introduction}

20 Canopy loss, for example through harvesting, is globally considered a threat to marine ecosystem, 21 seriously impacting biodiversity and functioning worldwide (Bruno and Bertness, 2001). Previous studies 22 have shown a wide range of responses to canopy removal, including reduction or loss of diversity and 23 reduction in primary productivity (Crowe et al., 2013). Fucoids and other intertidal macroalgae are 24 recognized as foundation species (sensu Jones et al., 1994) that have an important effect on abiotic conditions, community assembly and ecosystem functioning (Benedetti-Cecchi et al., 2001; Tait and 26 Schiel, 2011). Variations in their distribution may trigger changes in the whole system, such as shifts in community composition (Lilley and Schiel, 2006) or changes in the height and structure of the canopy itself (Golléty et al., 2008). 
Among them is Himanthalia elongata (L.) S. F. Gray, a brown alga forming dense stands on temperate rocky shores in the Northern hemisphere (Creed, 1995). Unlike other members of the Fucales, it has a biennial life cycle with four identifiable phases: vegetative growth, reproductive growth, reproduction (gametes are released and fuse to form zygotes) and a recruitment phase during which zygotes settle on the substratum (Stengel et al., 1999). Growth usually occurs between September and May, with a growth rate peak during spring when seawater temperatures are approx. $10-12^{\circ} \mathrm{C}$ (Stengel et al., 1999). The time of reproduction is from June to December, and is strongly site dependent, probably due to water temperature. This alga has a two-stage morphology: first, the 'button-like' stage is initially club-shaped, becoming peltate ('mushroom-shaped') when mature, about $2-3 \mathrm{~cm}$ in height and $2-4 \mathrm{~cm}$ in diameter, slightly dimpled in the middle, and attached to the substratum by a short stipe and discoid holdfast. Second, the mature peltate stage typically produces two long (up to $3 \mathrm{~m}$ ) thong-like reproductive receptacles (Stengel et al., 1999), hereafter referred as 'fronds'.

In addition to being ecologically important, $H$. elongata is also of commercial importance. It was traditionally harvested for centuries along the eastern Atlantic in Norway, France, Spain, Scotland, and Ireland for fertilizer, human food, and alginate extracts. H. elongata is currently harvested mainly as edible seaweed for human consumption in France, Ireland and Spain. Due to the high food value of $H$. elongata (Plaza et al., 2008), commercial harvesting of this species is likely to expand quickly. In France, H. elongata can be harvested all-year round but most of the harvest occurs between March and June, because after June large individuals are thick and grainy, thus less appealing for human consumption. In Brittany, annual harvested quantities of $H$. elongata have increased by 35\% between 2009 and 2013 (unpublished data). Despite the sustainably-oriented harvesting practices implemented for seaweeds in Europe these past few years, concern has raised about the broader impacts of harvesting (Isabel et al., 2011; Smale et al., 2013; Stagnol et al., 2016).

Demographic parameters have been used to examine the effect of harvesting in natural populations of brown macroalgae (e.g. Arenas and Fernández, 2000; Rivera and Scrosati, 2006; Santos, 1995). Size 
distributions result from differences in individual growth rates, consistent with the asymmetric competition hypothesis of dominance and elimination of smaller individuals by larger ones (Hara, 1988; Weiner and Thomas, 1986). The dynamics of size inequality as a function of plant size and density are important to understand not only the population structure, but also the interactions between individuals (Hara, 1988). Indeed, intraspecific facilitation (positive effects of density) is generally regarded as a major determinant of the dynamics of seaweed populations (Arenas and Fernández, 2000; Courchamp et al., 1999; Stephens and Sutherland, 1999). Creed (1995) confirmed the importance of density as a major regulator in $H$. elongata populations. Despite this, intraspecific relationships in macroalgal populations have usually been ignored (Paine, 1990) and their importance is poorly known. Besides, the development of seaweed population depends largely on the survival and growth of early post-settlement stages (Steen and Scrosati, 2004). In this context, demographic attributes, such as density, biomass, and size structure, could serve as ecological indicators to monitor the population dynamics of commercially important brown macroalgae.

One recent study realized on the same study site and at the same sampling dates as this study, found no or little impact of the harvesting of $H$. elongata on its associated community, while its percentage cover was significantly affected up to nine months after the disturbance (Stagnol et al., 2016). They showed, however, that 12 months after the disturbance, the percentage cover of $H$. elongata on the impacted zone had returned to a state comparable to the one observed on the undisturbed control zone.

Through experimental harvesting, followed by a 12-month monitoring, we tested the influence of the harvesting on the population dynamics of $H$. elongata and the hypothesis that the canopy could exert an effect on the other developmental stages (intraspecific relationships) throughout the recovery cycle of the population. This strategy allowed us to integrate population dynamics and intraspecific relationships in our understanding of macroalgal recovery patterns.

\section{$\underline{\text { Material and methods }}$}

\section{Study site}

This study was performed in Brittany, the French region in which commercial seaweed harvesting is the 
most important (> 90\% of macroalgae harvested in France). Field work was carried out on a site where H. elongata is commonly harvested, at Porspoder $\left(48^{\circ} \mathrm{N} 31.607^{\prime}, 4^{\circ} \mathrm{W} 46.169^{\prime}\right)$. This study site was also chosen for its large $H$. elongata standing crop and accessibility. This site is dominated by rocky substrata and presents a high water movement velocity.

\section{Experimental design and set-up}

The experimental design considered two treatments: one control (C) and one manipulated (M) where the canopy was removed, with five replicates each. Regarding $H$. elongata, the French legislation states that only individuals longer than $80 \mathrm{~cm}$ can be harvested. Harvest was realized in April 2012, by gathering by hand all individuals longer than $80 \mathrm{~cm}$ on a $115 \mathrm{~m}^{2}$ surface area. The fronds were cut at least $10 \mathrm{~cm}$ from the mushroom-like base. Sampling was done just before frond removal (T0) and then one month later (T1). Sampling frequency was then set to every two months, and then to every three months. Each sample is hereafter referred to as Tn where $n$ is the number of months since harvest. At each sampling date, five $0.1 \mathrm{~m}^{2}$ random quadrats were sampled on each treatment zones $(\mathrm{C}$ and $\mathrm{M})$

\section{Density, length, biomass, and developmental stage}

Individuals were classified as early club-shaped stage, mature vegetative mushroom-shaped stage and thong-like reproductive receptacles (fronds). Individuals of these developmental stages within the quadrats were counted and the maximal length of each frond was measured. Maximal length was used as size descriptor because length is probably crucial for survival and reproduction of individuals given that light is the primary resource for algae and that longer thalli intercept more light (Carpenter, 1990). As length and biomass were highly correlated in $\mathrm{H}$. elongata, the relationship between frond length and dry weight was examined using non-linear regressions. They were applied to fit parameters of the typical allometric power equation:

$$
\mathrm{DW}=\mathrm{a} \times \mathrm{FL}^{\mathrm{b}},
$$

equation 1

where DW represents dry weight $(\mathrm{g})$; FL, frond length $(\mathrm{cm})$, and $\mathrm{a}$ and $\mathrm{b}$ are constants. To fit the parameters, 36 individuals were collected in Roscoff $\left(48^{\circ} \mathrm{N} 43.686^{\prime}, 3^{\circ} \mathrm{W} 59.282^{\prime}\right)$ in front of the Station 
Biologique de Roscoff. An attempt was made to obtain samples representative of the full size range of the species. For each individual, the maximal length and dry weight, obtained after drying at $60^{\circ} \mathrm{C}$ for $48 \mathrm{~h}$, were recorded. An allometric length-weight equation was obtained using a power law equation. Based on density, the maximal length of each individual in the quadrats in each treatment at each sampling date was converted to dry weight using this equation. The average dry weight per $\mathrm{m}^{2}$ could then be estimated for each treatment at each sampling date, to investigate the temporal variation of $H$. elongata biomass, as well as stock recovery after harvesting.

\section{Size structure and inequality}

The frond size structure was determined for each zone and each sampling date, for which nine size classes (SCs) were previously established on the basis of frond length: $0-25 \mathrm{~cm}, 26-50 \mathrm{~cm}, 51-75 \mathrm{~cm}, 76-100 \mathrm{~cm}$, $101-125 \mathrm{~cm}, 126-150 \mathrm{~cm}, 151-175 \mathrm{~cm}, 176-200 \mathrm{~cm}$ and $>200 \mathrm{~cm}$. Frond size (length) inequality was determined for each zone and each sampling date by calculating the Gini coefficient using the length values for all the fronds of the five quadrats of each zone. This size-structure descriptor was selected here because it is the statistic that most accurately reflects the size hierarchy in populations (Weiner and Solbrig, 1984). The Gini coefficient ranges from a minimum of zero, when all individuals are equal in size (perfect equality), and a theoretical maximum of one in an infinite population in which every individual, except one, has a size of zero (perfect inequality). The Gini coefficient is frequently used as a measure of size inequality in seaweed populations (e.g. Arenas and Fernández, 2000; Rivera and Scrosati, 2006; Santos, 1995).

\section{Data analysis}

Multivariate analyses were made to test the effect of the experimental harvest disturbance using a permutational multivariate analysis of variance (PERMANOVA) design that included two factors: (i) controls vs. manipulated (CsM: 2 levels, fixed), and (ii) time (T: 6 levels, fixed and crossed). We examined biological responses to the harvesting disturbance for three demographic attributes (i.e. total density, dry standing biomass, Gini coefficient). We also examined multivariate differences in the density 
of the different developmental stages of $H$. elongata (i.e. adult fronds, button-like stages, and mushroomshaped stages), using the same design as above. Analyses were made with the PERMANOVA+ add-on package for PRIMER v6 (Anderson et al., 2008).

\section{$\underline{\text { Results }}$}

\section{Biomass, density and Gini coefficient}

The allometric relationship between frond length and dry weight was checked for $36 \mathrm{H}$. elongata fronds ranging from 8 to $281 \mathrm{~cm}$ :

$$
\mathrm{DW}=0.0041 \times \mathrm{FL}^{1.8744}, \mathrm{R}^{2}=0.93, \mathrm{p}<0.001
$$

equation 2

The average dry weight varied over time in both zones (Fig. 1a), with the highest values occurring in September (T5) on the control area. The temporal variation patterns were similar in both treatments, but the biomass was lower on the $\mathrm{M}$ treatment than on the $\mathrm{C}$ treatment (PERMANOVA, $\mathrm{p}<0.05$, Table 1 ), during the one-year period, except before harvesting (T0) and at the end of the study (T12) (Pairwise comparison, $\mathrm{p}>0.05$ ). Highest values of dry standing biomass were observed at $\mathrm{T} 5$ on the $\mathrm{C}$ treatment and at T12 on the M treatments. Total density varied significantly throughout the year from April 2012 to April 2013 (Fig. 1b) in both treatments (PERMANOVA, p < 0.05, Table 1). The density significantly decreased from $\mathrm{T} 1$ to $\mathrm{T} 3$ on the $\mathrm{M}$ treatment, and significantly increased from $\mathrm{T} 8$ to $\mathrm{T} 12$ on both treatments (Pairwise comparison, $\mathrm{p}<0.05$ ). Lowest values were observed between T3 and T8 on both treatments. The Gini coefficient varied significantly over time in both zones (Fig 1c, PERMANOVA, p < 0.05 , Table 1), with the highest values occurring at $\mathrm{T} 3$ and $\mathrm{T} 5$ for the $\mathrm{C}$ treatment and at $\mathrm{T} 1$ and $\mathrm{T} 8$ for the M treatment.

\section{Developmental stages}

The temporal variation patterns of the frond density (Fig. 2a) were significantly different between the two treatments (PERMANOVA, $\mathrm{p}=0.001$, Table 1). Thong-like reproductive receptacles (fronds), which indicate the possible occurrence of sexual reproduction, reached their highest frequency in the population 
at $\mathrm{T} 3$ in July in the $\mathrm{C}$ treatment (14\%) and at $\mathrm{T} 8$ in December in the M treatment (78\%). The peak of fronds observed at $\mathrm{T} 8$ in the $\mathrm{M}$ treatment was due to a high number of small fronds ( $\mathrm{n}=56$ ) shorter than $13 \mathrm{~cm}$, except for 2 individuals. At the same time in the $\mathrm{C}$ treatment, the fronds $(\mathrm{n}=10)$ consisted of $40 \%$ new and young fronds shorter than $6 \mathrm{~cm}$ and $60 \%$ of old and reproductive fronds longer than $200 \mathrm{~cm}$. Once reproductive tissues were lost in the $\mathrm{C}$ treatment, resulting in a loss of biomass, senescent fronds were observed at the end of the study (T12). In the M treatment, the biomass increased from T8 to T12 as the result of the growth of the short fronds observed at T8 (Fig. 1a).

The density of the mushroom-shaped stage (Fig. 2b) did not vary significantly throughout the year in either treatment zones and no significant differences were observed between them (PERMANOVA, $\mathrm{p}$ > 0.05 , Table 1 ). The density of the club-shaped stage varied significantly over time in both treatments (PERMANOVA, $\mathrm{p}<0.001$, Table 1). Finally, the density of the club-shaped stage (Fig. 2c) followed the same temporal pattern as the total density: it significantly decreased from $\mathrm{T} 1$ to $\mathrm{T} 3$ on the $\mathrm{M}$ treatment, and significantly increased from T8 to T12 on both treatments (Pairwise comparison, $\mathrm{p}<0.001$ ). Lowest values were observed between $\mathrm{T} 3$ and $\mathrm{T} 8$ on both treatments.

\section{Size structure and inequalities}

Frond size structure varied seasonally during the study period (Fig. 3). The first sample (T0) was taken in April 2012 during the reproductive growth phase of H. elongata. After the experimental harvest, two different population dynamics were observed in the different treatments.

In the $\mathrm{C}$ treatment, we observed that during the phase of reproductive growth, in spring (T0-T1), the thalli progressively shifted from smaller size classes to larger size classes, resulting in an increase in inequality (Fig. 1c), reaching a peak at the beginning of autumn (T5) $(\mathrm{G}=0.89)$. During this period, longer fronds (> $200 \mathrm{~cm}$ ) were recorded, representing $100 \%$ of the frond population (Fig. 3a). Then, the beginning of winter (T8) coincided with the start of the vegetative growth in the population and the emergence of recruits in smaller size classes. By the end of the study (T12), senescence caused reduction of thalli from the larger size classes to smaller size classes while the number of thalli from smaller size classes $(0-25 \mathrm{~cm}$ 
and $26-50 \mathrm{~cm}$ ) increased, due to the early growth of recruits. Due to these changes, the control zone reached its minimum inequality $(\mathrm{G}=0.36)$.

In the M treatment, harvest removed the majority of thalli, resulting in only one medium thallus $(66 \mathrm{~cm})$ observed at $\mathrm{T} 1$. The remaining thalli progressively increased in length while germlings (mushroom-shaped stage) shifted to the thong-like receptacle stage, resulting in an increased number of thalli in the smaller classes. The beginning of winter (T8) also coincided in the population with the emergence of recruits in the smallest size class $(0-25 \mathrm{~cm})$, which constituted almost $100 \%$ of all plants. By the end of the study (T12), the vegetative growth phase followed by the reproductive growth phase, resulted in the progressive shift of thalli from the smallest size class to larger size classes.

\section{$\underline{\text { Discussion }}$}

The regrowth of the canopy is expected to depend on newly recruited individuals and reproductive growth of algae that survived the disturbance. The recovery process of the $M$ treatment zone appeared to occur in three steps: first, the reproductive fronds of algae that survived the disturbance could reproduce since individuals shorter than $80 \mathrm{~cm}$ were not removed (T3). Second, the incomplete removal of the canopy may have been favorable for the growth and development processes, allowing these remaining individuals, as well as the early developmental stages (club-shaped and mushroom-shaped), to grow and occupy higher size classes. Third, the transition of these early developmental stages to the final adult stage was clearly visible in winter (T8) (Fig. 3b), possibly facilitated by the absence of a dense canopy of adults.

Eight months after removal, the number of fronds from the smallest size class $[0-25 \mathrm{~cm}]$ was highest in the $M$ treatment $\left(112 \pm 12.5\right.$ ind. $\left.\mathrm{m}^{-2}\right)$ than in the $\mathrm{C}$ treatment $\left(20 \pm 1.1\right.$ ind. $\left.\mathrm{m}^{-2}\right)$, suggesting that transition of these early developmental stages to the final adult stage, was more successful in the $\mathrm{M}$ treatment than in the $\mathrm{C}$ treatment. This may be explained by a lower competition between the adult stage forming a dense canopy and the early developmental stages living below the canopy. In the $\mathrm{M}$ treatment, the lack of a protective structure from the adult canopy during recruitment led to the creation of such micro-habitats, mainly with the rapid colonization of bare areas by red turf algae. It has been shown that the survival and 
growth of young buttons were highest in red algal turfs that protect the recruits from wave action and desiccation (Stengel et al., 1999). The role of these recruits in canopy recovery, however, was only visible at the end of the study, with an increase in the number of individuals in higher size classes, similar to the pattern observed in the $\mathrm{C}$ treatment. Canopy recovery was also linked with the recovery of the total biomass of $H$. elongata fronds, whose values at T12 were not different between the two treatments and were similar to those prior to the disturbance (T0). The stock renewal of $H$. elongata was, therefore, effective one year after harvesting.

In summary, in the $\mathrm{C}$ treatment, cohorts present at the start of the study (T0) grew and ultimately exerted a high intraspecific competition on the other developmental stages, by stopping further growth of juveniles. On the other hand, $\mathrm{M}$ treatment seems to have reduced intraspecific competition, allowing juveniles to grow. Then, the juveniles developed continuously, as seen in T8 with the high number of small fronds (Fig. 3b), permitting a fast recovery of size structure in this dynamic population.

Although it is widely reported that the structure and dynamics of most ecological communities are controlled partly by interactions between species (Bertness and Callaway, 1994; Bulleri, 2009; Edwards and Connell, 2012), the role of intraspecific relationships is less often integrated in studies of population dynamics. Recent research has emphasized the central role of positive species interactions as important drivers of community structure and ecosystem functioning (Brooker et al., 2008; Bulleri, 2009). This study showed negative intraspecific relationships (competition) in H. elongata in the undisturbed zone (C treatment). Positive effects of high densities on growth have been reported mainly in fucoid algae, where high densities may offer some protection against physical stress related to wave action and desiccation (Choi and Norton, 2005; Steen and Scrosati, 2004; Viejo and Aberg, 2001). In our work, although the impact of adult fronds on juvenile stages (club-shaped and mushroom-shaped button) was not directly measured, it seems likely that the presence of the canopy confers a disadvantage to the juvenile stage by reducing the availability of space, light and/or nutrients and by competing for those limiting resources (Carpenter, 1990). It appears that the H. elongata canopy plays a marked seasonal role, when the adult fronds are highly developed (in summer at T3 and T5). At that time, adult fronds do not preclude the 
presence of other developmental stages but somehow they delay or prevent their growth and development. Therefore, the removal of the canopy facilitates the transition from one developmental stage to another.

Overall our results suggest that the incomplete removal of the canopy (since individuals smaller than 80 $\mathrm{cm}$ remained) may have ensured the continued recruitment and re-growth of $H$. elongata, facilitating the regeneration of the exploited area. Growth and recruitment can be regulated by density-dependent processes operating at small-scale during the early stages of substrate colonization. Furthermore, the health and diversity of the surrounding macroalgal populations play an essential role in recovery, probably through the recruitment process and the magnitude of herbivorous grazing. Moreover, H. elongata being a seasonal canopy-forming species, its canopy loss on the impact sites was mediated by the natural and seasonal reduction in the H. elongata canopy on the control sites (also see Stagnol et al., 2016). From a conservation point of view, our results support the current legal harvesting techniques in France that enforce minimum harvesting size for specific seaweed including $H$. elongata, to minimize their impact on juvenile plants. Nowadays, $H$. elongata is also gathered by hand on shore in Ireland and Spain. Public authorities from these countries should introduce and enforce minimum harvesting size guidelines for $H$. elongata (if it is not already), and more generally, implement species specific regulations to ensure the sustainability of the algae resources and harvesting activities. In addition, species specific management requires ecological indicators sensitive to harvesting pressures and easy to measure by scientific observers and/or fishermen. In this context, demographic attributes are easily obtainable indicators that can be used as tools for stakeholders and policy makers.

The effects of other factors such as herbivory or extreme environmental conditions may also have operated on the intraspecific relationships of H. elongata. Indeed, recovery is assumed to be higher in the 253 presence of herbivores (Aquilino and Stachowicz, 2012), which are thought to promote succession by 254 grazing on early-successional fast-growing ephemeral species that would otherwise prevent establishment of perennial algae (Aquilino and Stachowicz, 2012). Understanding the balance between these factors is 
important to understand how settlement patterns affect population dynamics, although understanding the individual influences of each factor can be difficult (Stachowicz and Byrnes, 2006).

\section{$\underline{\text { Acknowledgments }}$}

The authors thank all those who helped carry out the fieldwork and anonymous reviewers for reviewing and improving the manuscript. Our study was funded by the ALGMARBIO project, InitiativeBioBretagne (IBB), FranceAgriMer (National Institute of Agricultural and Marine Products), the Brittany Regional Council, the Côte d'Armor Departmental Council, the European Fisheries Fund (EFF), and benefited from the support of the French Government run by the National Research Agency and with regards to the investment expenditure programme IDEALG ANR-10-BTBR-04.

\section{$\underline{\text { References }}$}

Anderson, M.J., Gorley, R.N., Clarke, K.R., 2008. PERMANOVA+ for PRIMER: Guide to Software and Statistical Methods. (PRIMER-E : Plymouth, UK.).

Aquilino, K.M., Stachowicz, J.J., 2012. Seaweed richness and herbivory increase rate of community recovery from disturbance. Ecology 93, 879-890. doi.org/10.1890/11-0457.1

Arenas, F., Fernández, C., 2000. Size structure and dynamics in a population of Sargassum muticum (Phaeophyceae). J. Phycol. 36, 1012-1020. doi:10.1046/j.1529-8817.2000.99235.x

Benedetti-Cecchi, L., Pannacciulli, F., Bulleri, F., Moschella, P.S., Airoldi, L., Relini, G., Cinelli, F., 2001. Predicting the consequences of anthropogenic disturbance: large-scale effects of loss of canopy algae on rocky shores. Mar. Ecol. Prog. Ser. 214, 137-150. doi:10.3354/meps214137

Bertness, M.D., Callaway, R., 1994. Positive interactions in communities. Trends Ecol. Evol. 9, 191-193. doi:10.1016/0169-5347(94)90088-4

Brooker, R.W., Maestre, F.T., Callaway, R.M., Lortie, C.L., Cavieres, L.A., Kunstler, G., Liancourt, P., Tielbörger, K., Travis, J.M.J., Anthelme, F., Armas, C., Coll, L., Corcket, E., Delzon, S., Forey, E., Kikvidze, Z., Olofsson, J., Pugnaire, F., Quiroz, C.L., Saccone, P., Schiffers, K., Seifan, M., Touzard, B., Michalet, R., 2008. Facilitation in plant communities: the past, the present, and the future. J. Ecol. 96, 18-34. doi:10.1111/j.1365-2745.2007.01295.x 
Bruno, J.F., Bertness, M.D., 2001. Habitat modification and facilitation in benthic marine communities, in: Marine Community Ecology (Bertness, M.D. et Al., Eds). Sinaeur, pp. 201-218.

Bulleri, F., 2009. Facilitation research in marine systems: state of the art, emerging patterns and insights for future developments. J. Ecol. 97, 1121-1130. doi:10.1111/j.1365-2745.2009.01567.x

Carpenter, R.C., 1990. Competition among marine macroalgae: a physiological perspective. J. Phycol. 26, 6-12. doi:10.1111/j.0022-3646.1990.00006.x

Choi, H.G., Norton, T.A., 2005. Competitive interactions between two fucoid algae with different growth forms, Fucus serratus and Himanthalia elongata. Mar. Biol. 146, 283-291. doi:10.1007/s00227004-1441-4

Courchamp, F., Clutton-Brock, T., Grenfell, B., 1999. Inverse density dependence and the Allee effect. Trends Ecol. Evol. 14, 405-410. doi:10.1016/S0169-5347(99)01683-3

Creed, J.C., 1995. Spatial dynamics of a Himanthalia elongata (fucales, Phaeophyta) population. J. Phycol. 31, 851-859. doi:10.1111/j.0022-3646.1995.00851.x

Crowe, T.P., Cusson, M., Bulleri, F., Davoult, D., Arenas, F., Aspden, R., Benedetti-Cecchi, L., Bevilacqua, S., Davidson, I., Defew, E., Fraschetti, S., Golléty, C., Griffin, J.N., Herkül, K., Kotta, J., Migné, A., Molis, M., Nicol, S.K., Noël, L.M.-L.J., Pinto, I.S., Valdivia, N., Vaselli, S., Jenkins, S.R., 2013. Large-scale variation in combined impacts of canopy loss and disturbance on community structure and ecosystem functioning. PLoS ONE 8, e66238. doi:10.1371/journal.pone.0066238

Duarte, L., Viejo, R.M., Martínez, B., deCastro, M., Gómez-Gesteira, M., Gallardo, T., 2013. Recent and historical range shifts of two canopy-forming seaweeds in North Spain and the link with trends in sea surface temperature. Acta Oecologica 51, 1-10. doi:10.1016/j.actao.2013.05.002

Edwards, M.S., Connell, S.D., 2012. Competition, a major factor structuring seaweed communities, in: Wiencke, C., Bischof, K. (Eds.), Seaweed Biology, Ecological Studies. Springer Berlin Heidelberg, pp. 135-156. 
Golléty, C., Migné, A., Davoult, D., 2008. Benthic metabolism on a sheltered rocky shore: role of the canopy in the carbon budget. J. Phycol. 44, 1146-1153. doi:10.1111/j.1529-8817.2008.00569.x

Halpern, B.S., Silliman, B.R., Olden, J.D., Bruno, J.P., Bertness, M.D., 2007. Incorporating positive interactions in aquatic restoration and conservation. Front. Ecol. Environ. 5, 153-160. doi:10.1890/1540-9295(2007)5[153:IPIIAR]2.0.CO;2

Hara, T., 1988. Dynamics of size structure in plant populations. Trends Ecol. Evol. 3, 129-133. doi:10.1016/0169-5347(88)90175-9

Isabel, S.-P., Serrão, E.A., Per, Å., 2011. Recovery after trampling disturbance in a canopy-forming seaweed population. Mar. Biol. 159, 697-707. doi:10.1007/s00227-011-1847-8

Jones, C.G., Lawton, J.H., Shachak, M., 1994. Organisms as ecosystem engineers. Oikos 69, 373-386. doi: $10.2307 / 3545850$

Lilley, S.A., Schiel, D.R., 2006. Community effects following the deletion of a habitat-forming alga from rocky marine shores. Oecologia 148, 672-681. doi:10.1007/s00442-006-0411-6

Moss, B., 1969. Apical meristems and growth control in Himanthalia elongata (S. F. Gray). New Phytol. 68, 387-397. doi:10.1111/j.1469-8137.1969.tb06451.x

Paine, R.T., 1990. Benthic macroalgal competition: complications and consequences. J. Phycol. 26, $12-$ 17. doi:10.1111/j.0022-3646.1990.00012.x

Plaza, M., Cifuentes, A., Ibáñez, E., 2008. In the search of new functional food ingredients from algae. Trends Food Sci. Technol. 19, 31-39. doi:10.1016/j.tifs.2007.07.012

Rivera, M., Scrosati, R., 2006. Population dynamics of Sargassum lapazeanum (Fucales, Phaeophyta) from the Gulf of California, Mexico. Phycologia 45, 178-189. doi:10.2216/05-47.1

Santos, R., 1995. Size structure and inequality in a commercial stand of the seaweed Gelidium sesquipedale. Mar. Ecol. Prog. Ser. 119, 253-263. doi:10.3354/meps119253

Sauvageau, M.C., 1918. Sur la dissémination et la naturalisation de quelques algues marines. Bull. Inst. Océan. Monaco 1-28. 
Smale, D.A., Burrows, M.T., Moore, P., O’Connor, N., Hawkins, S.J., 2013. Threats and knowledge gaps for ecosystem services provided by kelp forests: a northeast Atlantic perspective. Ecol. Evol. 3, 4016-4038. doi:10.1002/ece3.774

Stachowicz, J.J., Byrnes, J.E., 2006. Species diversity, invasion success, and ecosystem functioning: disentangling the influence of resource competition, facilitation, and extrinsic factors. Mar. Ecol. Prog. Ser. 311, 251-262. doi:10.3354/meps311251

Stagnol, D., Michel, R., Davoult, D., 2016. Unravelling the impact of harvesting pressure on canopyforming macroalgae. Mar. Freshw. Res. 67(1): 153-161 doi:10.1071/MF14198

Steen, H., Scrosati, R., 2004. Intraspecific competition in Fucus serratus and F. evanescens (Phaeophyceae: Fucales) germlings: effects of settlement density, nutrient concentration, and temperature. Mar. Biol. 144, 61-70. doi:10.1007/s00227-003-1175-8

Stengel, D., Wilkes, R., Guiry, M., 1999. Seasonal growth and recruitment of Himanthalia elongata (Fucales, Phaeophycota) in different habitats on the Irish west coast. Eur. J. Phycol. 34, 213-221. doi:10.1080/09670269910001736272

Stephens, P.A., Sutherland, W.J., 1999. Consequences of the Allee effect for behaviour, ecology and conservation. Trends Ecol. Evol. 14, 401-405. doi:10.1016/S0169-5347(99)01684-5

Tait, L.W., Schiel, D.R., 2011. Dynamics of productivity in naturally structured macroalgal assemblages: importance of canopy structure on light-use efficiency. Mar. Ecol. Prog. Ser. 421, 97-107. doi:10.3354/meps08909

Viejo, R.M., Aberg, P., 2001. Effects of density on the vital rates of a modular seaweed. Mar. Ecol. Prog. Ser. 221, 105-115. doi:10.3354/meps221105

Weiner, J., Solbrig, O.T., 1984. The meaning and measurement of size hierarchies in plant populations. Oecologia 61, 334-336. doi:10.1007/BF00379630

Weiner, J., Thomas, S.C., 1986. Size variability and competition in plant monocultures. Oikos 47, 211222. doi: $10.2307 / 3566048$ 


\section{Figures}
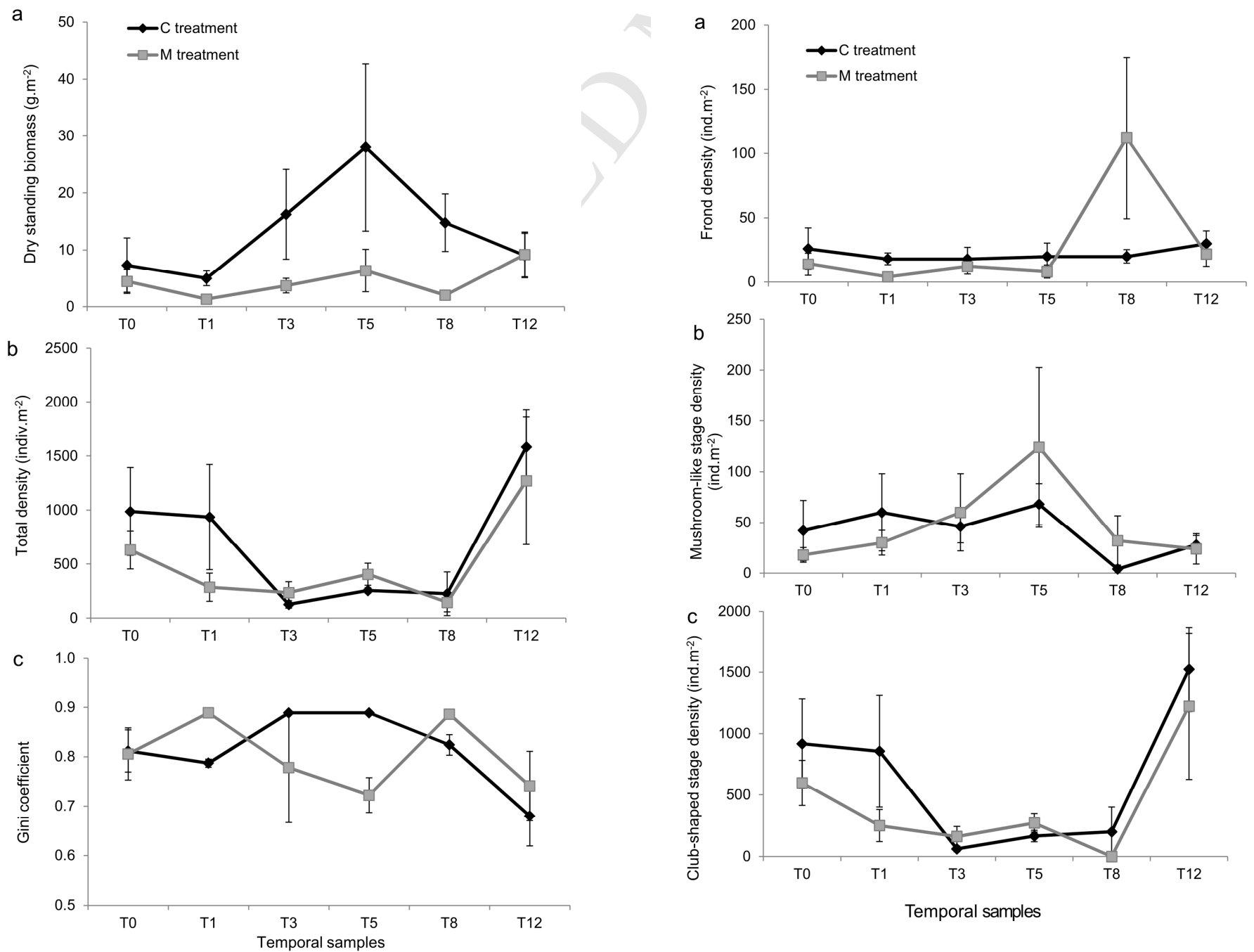

Fig. 1 Temporal variation (mean \pm SE) of dry standing biomass

Fig. 2 Temporal variation in densities (individual. $\mathrm{m}^{-2}$; mean 
Table 1 Summary of Permutational Analysis of Variance (PERMANOVA) for demographic parameters and developmental stages of Himanthalia elongata population. *: $\mathrm{p}<0.05 ; * *: \mathrm{p}<0.01$; $* * *: \mathrm{p}<0.001$. Factors: controls vs. manipulated (CsM: 2 levels, fixed), and time (T: 6 levels, fixed and crossed).

Demographic parameters

\begin{tabular}{|c|c|c|c|c|c|c|c|}
\hline \multirow{2}{*}{$\begin{array}{l}\text { Source of } \\
\text { variation }\end{array}$} & \multirow[b]{2}{*}{$\mathrm{df}$} & \multicolumn{2}{|c|}{$\begin{array}{l}\text { Dry standing } \\
\text { biomass }\end{array}$} & \multicolumn{2}{|l|}{ Total density } & \multicolumn{2}{|c|}{ Gini coefficient } \\
\hline & & MS & $\mathrm{F}$ & MS & $\mathrm{F}$ & MS & $\mathrm{F}$ \\
\hline$\overline{\mathrm{CsM}}$ & 1 & 8311.80 & $4.70 *$ & 1348.80 & 0.74 & 348.79 & $1.85 * * *$ \\
\hline $\mathrm{T}$ & 5 & 1625.40 & 0.92 & 7189.60 & $3.96 * * *$ & 227.24 & 1.21 \\
\hline CsMxT & 5 & 2078.00 & 1.18 & 1238.40 & 0.68 & 193.77 & 1.03 \\
\hline Res & 48 & 1767.70 & & 1813.40 & & 188.14 & \\
\hline
\end{tabular}

Developmental stages

\begin{tabular}{|c|c|c|c|c|c|c|c|}
\hline \multirow{2}{*}{$\begin{array}{l}\text { Source of } \\
\text { variation }\end{array}$} & \multirow[b]{2}{*}{$\mathrm{df}$} & \multicolumn{2}{|c|}{ Frond density } & \multicolumn{2}{|c|}{$\begin{array}{l}\text { Club-shaped stage } \\
\text { density }\end{array}$} & \multicolumn{2}{|c|}{$\begin{array}{l}\text { Mushroom-like } \\
\text { stage density }\end{array}$} \\
\hline & & MS & $\mathrm{F}$ & MS & $\mathrm{F}$ & MS & $\mathrm{F}$ \\
\hline$\overline{\mathrm{CsM}}$ & 1 & 22559.00 & $13.91 * * *$ & 1978.10 & 0.78 & 1746.40 & 0.54 \\
\hline $\mathrm{T}$ & 5 & 2126.10 & 1.31 & 9880.00 & $3.88 * * *$ & 4130.60 & 1.27 \\
\hline CsMxT & 5 & 1587.50 & 0.98 & 2133.70 & 0.84 & 2626.10 & 0.81 \\
\hline Res & 48 & 1622.10 & & 2548.00 & & 3254.20 & \\
\hline
\end{tabular}

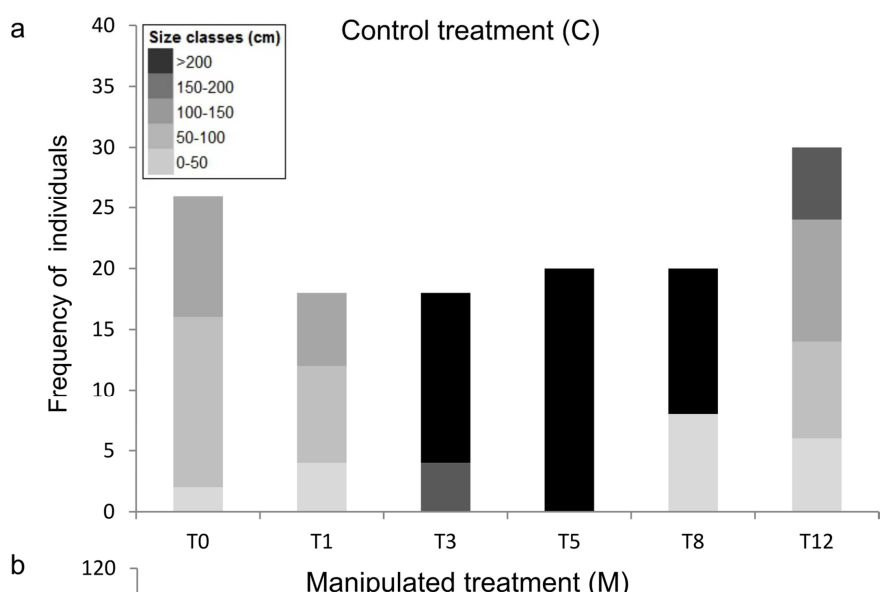

